\title{
Children draw more affiliative pictures following priming with third-party ostracism
}

\author{
Ruiting Song ${ }^{1}$ \\ Harriet Over ${ }^{2}$ \\ Malinda Carpenter ${ }^{1,3}$
}

${ }^{1}$ Department of Developmental and Comparative Psychology, Max Planck Institute for Evolutionary Anthropology, Leipzig, Germany

${ }^{2}$ Department of Psychology, University of York, York, United Kingdom

${ }^{3}$ School of Psychology and Neuroscience, University of St Andrews, St Andrews, Scotland

Acknowledgements: We thank Susanne Mauritz, Eva Siegert, Claudia Salomo, Katharina Graf, Felix Haiduk, Jana Urban, Tobias Schott, Georg Keller, Marcus Schmidt, Kassandra Sharren, Svea Taubert, Katja Weber, Theresa Mietzsch, Sascha Bölke, Peter Fröhlich, Tanja Urban, Rocco Buchholz, Maria Richter, Lars Uhlemann, Diana Scheffler, and Sylvio Tüpke, for help with testing and coding, Roger Mundry and Colleen Stephens for statistical support, and Tara Callaghan, Lars O. White, Maria Plötner, and Antonia Misch for advice.

Correspondence concerning this article should be addressed to Ruiting Song, Division of Cognitive Psychology, Faculty of Letters, Kumamoto University, Kumamoto, Japan. Contact: ruitingsong@gmail.com 


\begin{abstract}
Humans have a strong need to belong. Thus, when signs of ostracism are detected, adults often feel motivated to affiliate with others in order to re-establish their social connections. This study investigated the importance of affiliation to young children following priming with ostracism. Four- and 5-year-old children were primed with either ostracism or control videos and their understanding of, and responses to, the videos were measured. Results showed that children were able to report that there was exclusion in the ostracism videos, and that they recognized that the ostracized individual felt sad. Most interestingly, when subsequently asked to draw a picture of themselves and their friend, children primed with ostracism depicted relationships that were significantly more affiliative. Children drew themselves and their friend standing significantly closer together and adults rated their drawings as more affiliative overall. These findings introduce drawing as a useful new method for measuring social motivations and processes following an experimental manipulation, and demonstrate that affiliation is particularly important to children following even a vicarious experience of social exclusion.
\end{abstract}

Key words: ostracism, affiliation, drawing, social development, social motivation 


\section{Children draw more affiliative pictures following priming with third-party ostracism}

Humans need to belong. In fact, it has been argued that belonging is one of humans' most fundamental and pervasive needs (Baumeister \& Leary, 1995; Fiske, 2010).

Presumably this is because, throughout human evolutionary history, living in groups has been critical to survival (Brewer, 2007; Buss \& Kenrick, 1998; Kerr \& Levine, 2008; Spoor \& Williams, 2007). Thus if there is a risk of exclusion we should make every effort to repair our relationships with group members so as to regain our position in the group. Indeed, research shows that, following exclusion, adults' motivation to affiliate with others often increases, making them more likely to engage in affiliative behaviors such as mimicry, conformity, and cooperation (e.g., DeWall, 2010; DeWall, Maner, \& Rouby, 2009; Lakin, Chartrand, \& Arkin, 2008).

Children's social interactions often involve exclusion as well (e.g., Bierman, 2003; Casas et al., 2006; Crick, Casas, \& Mosher, 1997). Crick and Grotpeter (1995) have shown that even preschool children experience exclusion from peer interactions. This exclusion can have negative, long-term consequences for children's health, well-being, and academic achievement (Crick, 1996). It is thus of paramount importance to study children's understanding of ostracism and their reactions to it.

Experimental studies of ostracism in children have used a variety of different methods. In some studies, participants experience ostracism themselves. For example, Abrams and colleagues (2011) found that for 8- to 14-year-olds, being excluded from the online ball game developed by Williams, Cheung, and Choi (2000) threatened their basic need of belonging (as well as their needs for esteem, meaning, and control). In related work, Nesdale and Lambert (2007) found that when 8- and 10-year-old children imagined being excluded from a group, they reported that it would make them feel sad. Other studies have investigated children's evaluations of exclusion situations. For example, Killen and Rutland (2011) 
interviewed 4.5- and 5.5-year-old children and found that at both ages, children were able to make moral judgments about whether exclusion was acceptable or not in a given context.

Other recent work has investigated the effects of vicarious ostracism on children. This is a particularly useful approach as it enables one to investigate just how sensitive children are to ostracism without having to exclude children directly. In fMRI studies with 13-year-olds, Masten and colleagues $(2010 ; 2013)$ have demonstrated that simply observing someone else be excluded from an online ball game causes the mentalizing regions of the brain to be activated, along with the social pain regions among highly empathetic individuals. Watching someone else being ostracized has also been shown to decrease adolescents' mood (Will, Crone, van den Bos, \& Grüoğlu, 2013).

Watching others being ostracized has even been shown to affect the behavior of considerably younger children. Over and Carpenter (2009) showed 5-year-olds either two short videos depicting a group of animated shapes ostracizing another shape or two control videos with no ostracism, and found that children who had seen the ostracism videos subsequently imitated the actions of an experimenter more closely than children who had seen the control videos. Given that imitation can be an affiliative behavior (Lakin et al., 2008), Over and Carpenter interpreted these results as evidence that children's motivation to affiliate increased following priming with ostracism (see also Watson-Jones, Legare, Whitehouse, \& Clegg, 2014, for a replication and extension of these results).

However, it is not completely clear whether these results were produced by an affiliative motivation or some other social factor like increased encoding or recall of the demonstrated actions (previous research has shown that ostracism increases memory for social information; Gardner, Pickett, \& Brewer, 2000). In order to make a strong claim that affiliation is more important to young children following ostracism, it is necessary to provide converging evidence from another dependent variable. 
In the current study, children were shown the same priming videos as in Over and Carpenter (2009). To assess the importance of affiliation to them after watching the videos, they were then asked to draw a picture of themselves and their friend. If affiliation is more important to children following vicarious ostracism, then this should be reflected in their drawings: they should depict more affiliative social relationships following priming with ostracism than priming with control videos.

Drawing was chosen as a measure because it taps into children's spontaneous depictions of social relationships and provides rich information about children's current mindset. Drawing has been used to study symbolic and emotional development in children (e.g., Callaghan, 2008) and has also been used by clinical researchers to assist with assessments of emotional problems, experience with trauma, relationship situations, and other personal issues in older children and adults (e.g., Bombi, Pinto, \& Cannoni, 2007; Matto, 2007). However, until now it has not been used following an experimental manipulation to assess social processes and motivations in young children.

Two methods were used to assess the affiliative content of children's drawings. First, the proximity (i.e., distance in $\mathrm{mm}$ ) between the figures in the drawing was measured. The prediction was that children primed with ostracism would draw themselves and their friend standing closer together. From birth, infants' relationships with their caregivers are characterized by intimate proximity, and, growing up, people tend to seek proximity with those with whom they have intimate, positive relationships and avoid physical contact with those with whom they feel uncomfortable (Andersen, Gannon, \& Kalchik, 2013). There are also several empirical studies showing a connection between proximity and affiliation. For example, seating proximity has been used as a measure of affiliation in children (Olson, Newheiser, Eason, \& Hailey, 2013) as well as adults (e.g., Kawakami, Phills, Steele, \& Dovidio, 2007; Novelli, Drury, \& Reicher, 2010), and 7- to 11-year-old children use 
proximity as a cue to judge whether people are friends or foes (Neal, Neal, \& Cappella, 2013). Furthermore, Thomas and Gray (1992) have shown that proximity is linked to affiliation in children's drawings. When they asked 4- to 6-year-old children to draw a friend they like or a person they did not like along with themselves, they found that children drew themselves closer to the friend they like. The second measure used in the current study was a more general rating, by naïve adults, of each drawing as a whole for how affiliative it was, again with the prediction being that adults would rate the drawings of children in the ostracism condition as more affiliative. This measure thus included other possible indicators of affiliation beyond proximity.

Along with the drawing task, several comprehension questions were also included. As this was not done in previous studies, it remains unclear whether children actually understood the ostracism situation in the videos or not. Although it is well established that even very young children are capable of understanding moving shapes as animate agents with goals and dispositions (e.g., Gergely, Nádasdy, Csibra, \& Bíró, 1995; Hamlin, Wynn, \& Bloom, 2007), it is still unknown whether young children can extract complex social process like ostracism from them. Thus after watching the priming videos, children were asked what they thought had happened in the videos. In addition, children were asked to rate the mood of the protagonists in the videos. No previous studies have investigated whether children understand that being ostracized leads others to feel sad. Children were also asked to rate their own mood after watching the videos, to investigate whether simply watching others being ostracized would also decrease their own mood. Previous studies have shown that adolescents report feelings of sadness after observing third-person ostracism (Will et al., 2013); however, as yet there are no studies of this in young children.

Preschool children were of interest in the current study because they are among the youngest so far investigated in various ostracism studies using both verbal explicit measures 
and spontaneous behavior measures, e.g., imitation. It is well-documented that even these young children experience loneliness and exclusion (e.g., Crick et al., 1996) and prior experimental work has shown that they are sensitive to ostracism primes (Over \& Carpenter, 2009; Watson-Jones et al., 2014). Using this age range also enabled a preliminary investigation into when children's understanding of, and responses to, ostracism emerge developmentally. The drawings of children younger than 4 years of age would be too rudimentary for these types of analyses, so the current study focused on 4- and 5-year-olds. Five-year-olds have more experience interacting with social groups than do 4-year-olds, and have been shown to be very sensitive to group membership more generally (Dunham, Baron, \& Carey, 2011). Thus it was predicted that the older children would likely show a stronger difference between conditions than the younger children.

\section{Method}

\section{Participants}

Participants were 734 - and 5-year-olds $(M=59.5$ months, range 48.2 to 71.4 months; 36 boys). Four further children were tested but excluded because the test was inadvertently interrupted by kindergarten staff $(n=3)$ or because of experimenter error $(n=1)$. Three children refused to draw, two children turned the paper and drew in a portrait rather than landscape layout (and were thus dropped because the width of the paper is narrower in that layout and this might have impacted the proximity of the drawn figures), and four children stopped drawing in the middle with unclear pictures and failed to give an understandable description of their drawings. These children were included only for the other, verbal measures; thus there were 64 children in the final drawing dataset (32 boys), half in each condition. Half the children in each condition were 4-year-olds and half were 5-year-olds and there was no age difference between conditions. The 5-year-olds were tested first and the 4-year-olds were tested some months later. 
Children were recruited from and tested in their local kindergartens in a mid-sized city in Germany. All children had parental permission to participate. No SES or ethnicity data were collected.

\section{Design and Materials}

Children were randomly allocated to one of two conditions with the constraints that an equal number of males and females participated in each condition and that the ages of children in the two conditions were approximately matched. They first watched either two priming videos depicting ostracism or two control videos. After each video, children were asked the verbal questions and then they participated in the drawing task.

The priming stimuli were those used by Over and Carpenter (2009). In each condition they consisted of two short videos, each lasting approximately 1 minute. The videos were played on a 13-inch laptop computer. Each video featured moving shapes (blue pentagons in the first video and green horizontal teardrop shapes in the second video). The shapes did not have facial features or expressions, nor did they make any sound. Adult raters had previously interpreted the ostracism videos, but not the control videos, as depicting social exclusion. In each of the videos in the ostracism condition, a group of shapes entered and began interacting with each other (moving around together in the first video and passing a ball back and forth in the second video). A single shape, the protagonist, then entered and repeatedly approached the group but was not allowed to join in: the group of shapes repeatedly moved away from and rejected the protagonist. The videos used in the control condition were inclusion videos in the sense that they were identical to those in the ostracism condition with respect to the groups' behavior (thus the amount of information about inclusion was held constant across conditions). The rejected shape was replaced by a different type of object, one that was less likely to be seen as being socially excluded. This object (a blue, fly-like shape in the first video and a green, butterfly-like shape in the second 
video) made random movements around the screen. This shape was approximately the same size and color as the corresponding protagonists in the ostracism condition and the number and contingency of its movements were matched between conditions as well (see Over \& Carpenter, 2009, footnote 1, for more information.)

A child-friendly, 5-point scale composed of 5 schematic faces was used to help children to report the protagonists' and their own moods. The schematic faces were printed in a row: from left to right, a very sad face, a somewhat sad face, a neutral face, a somewhat happy face, and a very happy face. These expressions were depicted by the shape of the mouth. For the drawing task, a green marker and a piece of paper $(15 \mathrm{~cm} \times 23 \mathrm{~cm})$ were used.

A final video with all shapes playing together was shown to children in both conditions at the very end of the session. This was done to alleviate any negative feelings that might have been induced by the ostracism video and to model inclusive behavior.

\section{Procedure}

Children sat beside the experimenter (E) in a quiet room in their kindergarten facing the laptop computer. E was not told the hypotheses of the study or what was being measured with the drawing task. E said to children that she needed to write something down and that in the meantime they could watch a video. She started the first video and turned away to write. When the first video finished, it paused on the last frame with a click sound. E then turned back to children and asked them the comprehension questions: first, what happened in the video, and second, "What happened to him/her?" while pointing to the protagonist (the choice of him or her matched the gender of the child). After children answered these questions, E brought out the face scale, and, pointing to the protagonist, asked children the mood questions: "How do you think he/she feels: very sad, a little sad, ok, a little happy, or very happy?" pointing in turn to each of the faces on the scale. Then she asked children, 
“How do you feel after the video: very sad, a little sad, ok, a little happy, or very happy?" E then started the second video and, when it ended, asked children the same questions again, exactly as before.

Then E gave children the drawing materials and said, "Now it is time to draw. Draw a picture of you and your friend." The screen of the laptop was angled down during this period so as not to distract children from the drawing task. E let children continue drawing until they told her they were finished. E then looked at the picture and asked who each person was and what they were doing, to be sure which individuals were the child and friend, and to be able to identify any unclear elements in the drawing for later coding. If children were reluctant to draw, E prompted them by repeating the instruction, but went on to the final video of all the shapes playing together if they still refused to draw after two prompts.

\section{Coding and Reliability}

Children's answers to the comprehension and mood questions, and the total time they spent drawing (see below), were coded from videotapes of the session. The drawing measures were coded directly from children's drawings.

Comprehension and mood questions. For each video, children's answers to the comprehension questions were coded using a scale ranging from $0-2$ according to the extent to which they referenced ostracism: clear reference to ostracism (2), related but less explicit reference to ostracism (1), or no reference to ostracism at all (0). Children received a score of 2 if they said that the group does not want/excludes the protagonist, that the protagonist wants to join but cannot, and/or that the protagonist is left out (e.g., "Those two didn't let her play along" or "They kicked him out"). Children received a score of 1 if they said that the protagonist is alone and/or that the protagonist is in a negative mood (note that this was considered a relevant response because the shapes expressed no emotions and thus this had to be inferred from the situation depicted). To assess children's overall comprehension of the 
videos, the average of the scores children received for each video was used in analyses. Both coders were unaware of the hypotheses and the condition to which children had been assigned. The reliability coder coded a randomly-chosen selection of $27.4 \%$ of children $(n=$ 20). Agreement was excellent (Cohen's kappa $=.86)$. Throughout, whenever there were disagreements, the main coder's coding was used for analyses.

Children's answers to the questions regarding the protagonists' and their own mood were coded from the face scale: they were given a score ranging from 0 (very sad) to 4 (very happy). Both coders were unaware of the hypotheses and the condition to which children had been assigned. The reliability coder coded a randomly-chosen selection of $27.4 \%$ of children $(n=20)$. Agreement was excellent (Cohen's kappa $=.88)$.

Drawing task. The main measure of interest was the distance between the child and his or her friend in the drawings. This was measured in millimeters between the two closest points of each individual along the horizontal axis (for a similar measure see Bombi et al., 2007). If children drew the individuals touching or overlapping (e.g., holding hands), the distance was coded as 0 millimeters. If children drew more than two individuals $(n=11,5$ in the ostracism condition), the distance between the two closest figures was coded. If children drew only themselves ( $n=2$, both in the control condition), they were given the maximum distance in the dataset plus one millimeter. As it turned out, the individuals depicted in children's drawings varied in size both across children and, sometimes, within drawings. According to Freeman (1980), preschool children tend to draw later components relative to those already drawn. Hence the size of the first drawn individual was controlled for in the analyses. The size of this figure was measured in millimeters along the horizontal axis between its two widest points. The reliability coder, who was unaware of hypotheses and condition, coded a randomly-selected $26.6 \%$ of the pictures $(n=17)$. For the closest distance measure, Pearson's $r(15)=.96, p<.001$, with no difference between coders, $t(32)=-0.03, p$ 
$=.98, d=-0.01$. For the size of the first drawn individual, Pearson's $r(15)=1.00, p<.001$, with no difference between coders, $t(32)=0.08, p=.93, d=0.03$.

To validate the proximity measure as a measure reflecting affiliation, and to provide converging evidence from a different approach, 10 naïve adult coders ( 5 male, all 10 unaware of the condition children were in and the hypotheses of the study) were asked to rate all the drawings based on how affiliative they thought they were. The raters were first asked to look at all the drawings one by one and then to give a score to each one based on their general impression using a 7-point Likert scale, ranging from 1 (not at all affiliative) to 7 (very affiliative). The scores of the 10 raters were then averaged for each picture.

When examining children's drawings, it was noticeable that children in the ostracism condition often seemed to take more care over their drawings; hence a supplementary set of coding involved the time spent on the drawing (in seconds) and the complexity - in particular the social complexity - of the drawing. For complexity, the number of social elements in the picture was counted. Elements included body parts like head, hair, eyes, ears, fingers, etc., both on children and their friend and on any other people or objects (e.g., suns, kites; see below) they drew. To control for the number of objects and people drawn, each type of element was counted only once per picture regardless of the number of them drawn. For example, regardless of whether children drew 1 ear or 4 in their picture, they would get a score of 1 for the element "ear." Quite a few children drew background, non-social elements as well; however, since especially for the 4-year-olds not all of these were recognizable and thus codeable (e.g., they often consisted of scribbles or lines for which children could not give a comprehensible explanation), these elements were not included in the analyses. For reliability, for time spent on the drawing, Pearson's $r(14)=.96, p<.001$, with no difference between coders, $t(30)=-0.02, p=.99, d=-0.01$. For number of social elements, Pearson's $r(15)=.92, p<.001$, with no difference between coders, $t(32)=0.23, p=.82, d=0.08$. 


\section{Results}

Given the distribution of ages, and to provide a more fine-grained analysis of developmental change, age is treated as a continuous variable in all cases and centered to test for an age $\mathrm{x}$ condition interaction in the regression analyses. For the categorical variables, 0 $=$ control condition and $1=$ ostracism condition, and $0=$ females and $1=$ males. For multiple regression tests, main effects (i.e., gender, age, and condition) were entered in step 1 and the interaction of interest (i.e., age x condition) was entered in step 2 (a condition x gender interaction, although not hypothesized, was tested for each model but was non-significant and thus dropped in all cases). Regression coefficients with 95\% confidence intervals, standard errors, beta values, $t$ values, and adjusted $R$ squared changes can be found in Table 1 .

Scatterplots showing individual data for each measure can be found in the Supplementary Materials online.

\section{Comprehension questions}

The regression equation was significant, $F(3,69)=9.95, p<.001$. There was a main effect of condition: Children in the ostracism condition $(M=0.68, S E=0.13)$ referenced ostracism more clearly than did children in the control condition $(M=0.12, S E=0.04), \beta=$ $.44, p<.001$. There was an effect of age, $\beta=.32, p=.002$, but no effect of gender, $\beta=.04, p$

$=.67$. These main effects were qualified by a significant age $\mathrm{x}$ condition interaction, $\beta=.33$, $p=.016$. As Figure 1 shows, there was a positive relation between age and scores on the comprehension questions for children in the ostracism condition: with increasing age, children were more likely to reference ostracism (i.e., the slope of this regression line was significantly different from zero, $t(69)=4.08, p<.001$; Aiken \& West, 1991); but no such relation was found for children in the control condition $(t(69)=0.73, p=.47)$. 


\section{Protagonist's Mood}

The regression equation was significant, $F(3,65)=5.30, p=.002$. There was a main effect of condition: Children reported that the protagonists felt sadder in the ostracism $(M=$ $0.84, S E=0.15)$ than in the control condition $(M=1.79, S E=0.21), \beta=-.41, p<.001$. Neither age, $\beta=.13, p=.25$, nor gender, $\beta=.14, p=.20$, predicted children's report of the protagonists' mood.

\section{Children's Own Mood}

The regression equation did not reach significance, $F(3,69)=0.14, p=.94$. On average, children reported being in a positive mood in both the ostracism condition, $M=$ 2.97, $S E=0.19$, and the control condition, $M=3.11, S E=0.16, \beta=-.07, p=.57$. Neither age, $\beta=.04, p=.75$, nor gender, $\beta=.003, p=.98$, predicted children's report of their own mood. All children also reported being in a positive mood following the final video at the end of the session.

\section{Drawing Task}

Figure 2 presents representative drawings from each condition.

Distance between self and friend. To assess the effects of condition, age, their interaction, and gender, a single model was run that controlled for the size of the first drawn figure. Since children's responses for this measure largely consisted of zeroes $(57.8 \%$ of the total responses) but also comprised some fairly large values (maximum $=48$ ), a zero-inflated model with negative binomial error function was run. This model not only allows one to estimate the overall effects of the predictors on the response, but also creates two regression equations: the zero part and the count part. The zero part is a binomial logistic test that allows one to assess which variables predict whether or not the figures touch (i.e., distance $=$ $0 \mathrm{~mm})$. The count part is a negative binomial logistic test that allows one to answer which variables predict the differences in drawing distance between groups. The same model 
structure (i.e., main effect and interactions included) was assumed for both parts of the model. The model was fitted in $\mathrm{R}$ (version 3.0.2, R Core Team, 2013) using the function zeroinfl of the R-package pscl (Jackman 2012; Zeileis, Kleiber, \& Jackman, 2008). To estimate the overall significance of condition and its interaction with age, the full model as described above was compared with a null model (Forstmeier \& Schielzeth, 2011) using a likelihood ratio test (Dobson, 2002).

Overall, there was a clear impact of the predictors on the response (likelihood ratio test comparing full and null model: $\left.\chi^{2}=20.62, \mathrm{df}=8, p=.008\right)$. A significant interaction was found between age and condition on the zero part of the model (estimate $\pm \mathrm{SE}=1.98 \pm$ $0.69, \mathrm{z}=2.89, p=.004)$. With regard to the zero part, the interaction revealed that in the ostracism condition the probability of drawing figures touching each other increased with age, whereas in the control condition the probability decreased with age. In the ostracism condition, $65.6 \%$ of children $(n=21)$ drew the figures touching each other and in the control condition, $50 \%$ of children did so $(n=16)$.

With regard to the count part, as the interaction between age and condition was nonsignificant (estimate $\pm \mathrm{SE}=0.19 \pm 0.24, \mathrm{z}=0.81, p=.42$ ), it was dropped from the model and the effect of the other predictors on the response was investigated. This analysis showed a significant effect of condition (estimate $\pm \mathrm{SE}=-0.56 \pm 0.27, \mathrm{z}=-2.13, p=.033$ ): children in the ostracism condition $(M=4.41 \mathrm{~mm}, S E=1.62)$ were more likely to draw the figures standing closer to each other than were children in the control condition $(M=9.44 \mathrm{~mm}, S E=$ 2.53). Neither age (estimate $\pm \mathrm{SE}=-0.21 \pm 0.12, \mathrm{z}=-1.75, p=.080)$ nor gender (estimate \pm $\mathrm{SE}=-0.40 \pm 0.24, \mathrm{z}=-1.65, p=.098)$ had a significant effect. (Intercept model: estimate + $\mathrm{SE}=3.22+0.21, \mathrm{z}=15.28, p<.001 ;$ effect of the size of the first drawn figure: estimate \pm $\mathrm{SE}=0.35 \pm 0.14, \mathrm{z}=2.41, p=.016$. 
Adults' rating of affiliation. The regression equation was significant, $F(3,60)=$ 18.01, $p<.001$. There was a main effect of condition: Children's drawings in the ostracism condition $(M=4.45, S E=0.25)$ were rated as higher in affiliation than were those in the control condition $(M=3.96, S E=0.21), \beta=.19, p=.045$. Girls $(M=4.87, S E=0.20)$ also scored higher than boys $(M=3.55, S E=0.21), \beta=-.45, p<.001$, and children scored higher with increasing age, $\beta=.44, p<.001$.

Time spent. The regression equation was significant, $F(3,59)=5.18, p=.003$. There was a main effect of condition: Children in the ostracism condition $(M=176.55 \mathrm{~s}, S E$ $=20.67)$ spent a longer time on the drawing task than children in the control condition $(M=$ $112.66 \mathrm{~s}, S E=11.24), \beta=.31, p=.009$. There was an effect of gender, with girls $(M=$ $172.84 \mathrm{~s}, S E=19.39)$ spending longer on their drawings than boys $(M=116.25 \mathrm{~s}, S E=$ 13.71), $\beta=-.33, p=.007$, but no effect of age, $\beta=.06, p=.63$.

Number of social elements. The regression equation was significant, $F(3,60)=$ $11.80, p<.001$. There was a marginal effect of condition: Children in the ostracism condition tended to draw more social elements $(M=11.47, S E=0.56)$ than did children in the control condition $(M=10.31, S E=0.45), \beta=.21, p=.050$. There was an effect of gender, with girls $(M=12.28, S E=0.43)$ drawing more social elements than boys $(M=9.50$, $S E=0.47), \beta=-.45, p<.001$. With increasing age, children drew more social elements, $\beta=$ $.31, p=.004$.

\section{Discussion}

The current study investigated whether 4- and 5-year-old children understand ostracism situations and how they respond to them. It was found that, overall, children understood the rather abstract depictions of ostracism presented to them in the videos. Despite the absence of cues like facial or vocal expressions, some children offered such comprehensive descriptions as, “Those there played with the ball and he wasn't allowed to 
play along...he is sad now," and "They didn't want to have him...they kicked him out." Although the ability to describe the videos improved with age, even some of the youngest children showed some signs of understanding. Furthermore, children at all ages judged that the protagonist felt sad following exclusion. This is the first published evidence that young children recognize that ostracism has negative consequences for the victim. Thus young children are already sensitive to mere hints of social exclusion and understand the emotional consequences of such situations, even as outside observers of others' interactions. These videos thus constitute a useful tool for assessing reactions to ostracism.

The results from the drawing task demonstrate that children are more likely to think about or value affiliation following observation of ostracism. Children primed with ostracism drew more affiliative pictures than children in the control condition, as evidenced by several different measures. Children in the ostracism condition were significantly more likely to draw themselves and their friend standing close together than were children in the control condition and, with increasing age, children were more likely to draw themselves and their friend touching (e.g., holding hands) in the ostracism condition but not in the control condition. Furthermore, the drawings of children in the ostracism condition were rated as higher in affiliation by 10 naïve adult raters. Taken together, these measures provide strong evidence that children's drawings had more affiliative content following a vicarious experience of ostracism.

One interesting, although unpredicted, finding was that children primed with ostracism generally took more care over their drawings - spending longer on them and producing more socially complex pictures. One possible explanation for this is that children in the ostracism condition took more care with their drawings in an attempt to comfort themselves following the negative experience of ostracism. However, this explanation seems implausible, as children in that condition did not report more negative mood than children in 
the control condition. Instead, we think this may have been related to affiliative motives too: perhaps children took more time over their drawings in an attempt to please, and thus ingratiate themselves with, the experimenter. Future research should look into this possibility.

Turning to the question of developmental emergence and change, there was an interaction between age and condition in some of the comprehension and drawing measures. First, older children were better able to explain what happened in the ostracism videos than were younger children. One plausible reason for this is simply that their verbal abilities were more advanced. Given the younger children's success on the protagonist's mood measure, it is likely that they had some understanding of what was happening in the videos. In future research it would be interesting to investigate the younger children's understanding with more focused questions about the events in the video (e.g., "Did that one want to play with the others or alone?"). There was also an interaction between age and condition in one of the proximity measures of the drawing task: whether children drew themselves and their friend touching or not. Plausible reasons for this could be that affiliative motivations may be less strongly triggered by ostracism in younger children or that the drawing task was more difficult for the younger children. Another possible explanation relates to how younger children behaved during testing: they tended to need more prompts from the experimenter to finish their drawing and more reminders of the instructions (i.e., draw both themselves and their friend). It could be that these prompts, and the increased social interaction with the experimenter that necessarily resulted from them, weakened the effect of the ostracism prime. However, no such interactions with age were found for the other two main drawing measures: the distance between the self and the friend and adults' ratings of affiliation in the drawings. Thus younger children were already showing the effect. It will be interesting for future 
research to utilize different dependent variables to investigate even younger children's sensitivity to ostracism.

One remaining question is why children did not report a more negative mood themselves after watching the ostracism videos. In previous studies, adult and adolescent participants reported feeling sad after both observing and directly experiencing ostracism (e.g., Wessellmann, Bagg, \& Williams, 2009; Will et al., 2013; Williams, 2007). However in the current study, while children reported that the ostracized protagonists felt sad, they did not report feeling sad themselves. There are several possible reasons for this. First, it is possible that, for younger children, watching ostracism as an observer is different from experiencing it in person: Perhaps this engenders sympathy for the ostracized individual in young children but not direct sadness in themselves. This may especially be the case in the current study because the ostracized protagonists were just shapes, rather than people. However watching these shapes did influence children's drawings, so they clearly made some sort of connection between the shapes and themselves, even if it was not an emotional one. Second, it is possible that procedural details contributed to this finding: The order of the mood questions was not counterbalanced, so it could be that after children said that the protagonist was feeling sad, they compared their own situation to his and realized that they were not in the same situation and thus were in a more positive mood. A third, more basic possibility is simply that perhaps children did not have introspective awareness into their own mood. It would be interesting for future research to examine this finding further and to investigate the similarities and differences between experiencing and observing social exclusion.

Another open question is the mechanism by which the ostracism videos led to enhanced affiliative motivation. One possibility is that the effect was mediated by empathy for the ostracized individual (Masten et al., 2010; 2013). However, again, children in the 
ostracism condition did not report that they themselves felt sad, casting doubt on this explanation. Another possibility is that the effect was mediated by a more cognitive process of taking the perspective of the ostracized individual (Wesselmann et al., 2009). With this in mind, it would be interesting for future research to assess whether asking children to take the perspective of the protagonist in the videos increases the strength of the effect. Finally, it is possible that the ostracism primes triggered the thought of affiliation more directly and automatically (Bargh, Schwader, Hailey, Dyer, \& Boothby, 2012). Understanding the mechanism(s) underlying this behavior is an important aim for future research.

It is interesting to note that, at least in adults and older children, ostracism does not always lead to affiliation. Sometimes it leads to aggression (Twenge, Baumeister, Tice, \& Stucke, 2001) and sometimes to withdrawal (Barkley, Salvy, \& Roemmich, 2012). A number of factors may be responsible for these different responses, for example Warburton, Williams, and Cairns (2006) suggested that the amount of control individuals feel over their situation could be important. It would be interesting for future research to examine whether, under certain circumstances, ostracism (whether vicarious or direct) might lead to these other types of social responses in young children as well.

The current research contributes a novel method for studying social processes in young children: drawing. Previous research has shown that children can depict different types of relationships in their pictures with, for example, proximity, size, color, and similarity (e.g., Milbrath, 2007; Thomas \& Gray, 1992). This is the first study to use drawing as a measure of social processes and motivation following an experimental manipulation. As a task, drawing is straightforward to explain, simple to implement, and familiar to young children. As it needs little verbal instruction and taps into implicit processing, it can be used to assess children's spontaneous responses to social situations and thus provide a window into what children are thinking about or what is important to them at that moment. 
In summary, this study contributes important information to the understanding of the value children place on relationships with their group members. Previous research has shown, for example, that early in development, children prefer members of their own groups to members of other groups (e.g., Dunham et al., 2011; Kinzler, Dupoux, \& Spelke, 2007) and that they conform to the opinions of those around them (Corriveau \& Harris, 2010; Haun \& Tomasello, 2011). Here we focus on social motivation and provide evidence that young children are not only sensitive to mere hints of social exclusion but also that affiliation is important to them after observing ostracism. In doing so, we demonstrate that the need to belong exerts a powerful influence on our behavior from early in development. 


\section{References}

Abrams, D., Weick, D., Thomas, D., Colbe, H., \& Franklin, K.M. (2011). On-line ostracism affects children differently from adolescents and adults. Developmental Psychology, 29, 110-123. doi:10.1348/026151010x494089

Andersen, P., Gannon, J., \& Kalchik, J. (2013). Proxemic and haptic interaction: the closeness continuum. In J.A. Hall \& M.L. Knapp (Eds.), Nonverbal communication (pp. 295-323). Berlin, Germany: De Gruyter Mouton.

Aiken, L.S., \& West, S.G. (1991). Multiple regression: Testing and interpreting interactions. Newbury Park, CA: Sage.

Bargh, J.A., Schwader, K.L., Hailey, S.E., Dyer, R.L., \& Boothby, E.J. (2012). Automaticity in social-cognitive processes. Trends in Cognitive Sciences, 16, 593-605. doi:10.1016/j.tics.2012.10.002

Barkley, J.E., Salvy, S., \& Roemmich, J.N. (2012). The effect of simulated ostracism on physical activity behavior in children. Pediatrics, 129, 659-666. doi:10.1542/peds.2011-0496d

Baumeister, R.F., \& Leary, M.R. (1995). The need to belong: desire for interpersonal attachments as a fundamental human motive. Psychological Bulletin, 117, 497-529. doi:10.1037//0033-2909.117.3.497

Bierman, K.L. (2003). Peer rejection: Developmental processes and intervention strategies. New York: Guilford Press.

Bombi, A.S., Pinto, G., \& Cannoni, E. (2007). Pictorial assessment of interpersonal relationships. Firenze, Italy: Firenze University Press.

Brewer, M.B. (2007). The importance of being we: Human nature and intergroup relations. American Psychologist, 62, 728-738. doi:10.1037/0003-066x.62.8.728

Buss, D.M., \& Kenrick, D.T. (1998). Evolutionary social psychology. In D.T. Gilbert, S.T. 
Fiske, \& G. Lindzey (Eds.), The handbook of social psychology (4 ${ }^{\text {th }}$ ed., pp. 9821026). New York: Oxford University Press.

Callaghan, T.C. (2008). The origins and development of pictorial symbol functioning. In C. Milbrath \& H.M. Trautner (Eds.), Children's understanding and production of pictures, drawings, and art (pp. 21-32). Cambridge, MA: Hogrefe \& Huber.

Casas, J.F., Weigel, S.M., Crick, N.R., Ostrov, J.M., Woods, K.E., Jansen Yeh, E.A., \& Huddleston-Casas, C.A. (2006). Early parenting and children's relational and physical aggression in the preschool and home contexts. Journal of Applied Developmental Psychology, 27, 2209-2227. doi:10.1016/j.appdev.2006.02.003

Corriveau, K.H. \& Harris, P.L. (2010). Preschoolers (sometimes) defer to the majority in making simple perceptual judgments. Developmental Psychology, 46, 437-445. doi:10.1037/a0017553

Crick, N.R. (1996). The role of relational aggression, overt aggression, and prosocial behavior in the prediction of children's future social adjustment. Child Development, 67, 2317-2327. doi:10.1111/j.1467-8624.1996.tb01859.x

Crick, N.R., Casas, J.F., \& Mosher, M. (1997). Relational and overt aggression in preschool. Developmental Psychology, 33, 579-588. doi:10.1037/0012-1649.33.4.579

Crick, N.R., \& Grotpeter, J.K. (1996). Children's treatment by peers: Victims of relational and overt aggression. Development and Psychopathology, 8, 367-380. doi:10.1017/s0954579400007148

DeWall, C.N. (2010). Forming a basis for acceptance: Excluded people form attitudes to agree with potential affiliates. Social Influence, 5, 245-260. doi:10.1080/15534511003783536

DeWall, C.N., Maner, J.K., \& Rouby, D.A. (2009). Social exclusion and early-stage interpersonal perception: Selective attention to signs of acceptance. Journal of 
Personality and Social Psychology, 96, 729-741. doi:10.1037/a0014634

Dobson A.J. (2002). An introduction to generalized linear models. Boca Raton: Chapman \& Hall/CRC.

Dunham, Y., Baron, A.S., \& Carey, S. (2011). Consequences of "minimal” group affiliations in children. Child Development, 82, 793-811. doi:10.1111/j.14678624.2011.01577.x

Fiske, S.T. (2010). Social beings: Core motives in social psychology ( $2^{\text {nd }}$ Ed.). New York: Wiley.

Forstmeier, W. \& Schielzeth, H. (2011). Cryptic multiple hypotheses testing in linear models: Overestimated effect sizes and the winner's curse. Behavioral Ecology and Sociobiology, 65, 47-55. doi:10.1007/s00265-010-1038-5

Freeman, N.H. (1980). Strategies of representation in young children: Analysis of spatial skills and drawing processes. London: Academic Press.

Gardner, W.L., Pickett, C.L., \& Brewer, M.B. (2000). Social exclusion and selective memory: how the need to belong influences memory for social events. Personality and Social Psychology Bulletin, 26, 486-496. doi:10.1177/0146167200266007

Gergely, G., Nádasdy, Z., Csibra, G., \& Bíró, S. (1995). Taking the intentional stance at 12 months of age. Cognition, 56, 165-193. doi:10.1016/0010-0277(95)00661-h

Hamlin, J.K., Wynn, K., \& Bloom, P. (2007). Social evaluation by preverbal infants. Nature, 450, 557-559. doi:10.1038/nature06288

Haun, D.B. \& Tomasello, M. (2011). Conformity to peer pressure in preschool children. Child Development, 82, 1759-67. doi:10.1111/j.14678624.2011.01666.x Jackman, S. (2012). pscl: Classes and Methods for R Developed in the Political Science Computational Laboratory, Stanford University. Department of Political Science, Stanford University. Stanford, California. R package version 1.04.4. 
Kawakami, K., Phills C.E., Steele J.R., \& Dovidio J.F. (2007). (Close) distance makes the heart grow fonder: Improving implicit racial attitudes and interracial interactions through approach behaviors. Journal of Personality and Social Psychology, 92, 957971. doi:10.1037/0022-3514.92.6.957

Kerr, N.L., \& Levine, J.L. (2008). The detection of social exclusion: Evolution and beyond. Group Dynamics, Special Issue: Evolutionary Approaches to Group Dynamics, 12, 39-52. doi:10.1037/1089-2699.12.1.39

Killen, M. \& Rutland, A. (2011). Children and social exclusion: Morality, prejudice, and group identity. Oxford, UK: Wiley-Blackwell.

Kinzler, K.D., Dupoux, E., \& Spelke, E.S. (2007). The native language of social cognition. Proceedings of the National Academy of Sciences, 104, 12577-12580. doi:10.1073/pnas.0705345104

Lakin, J.L., \& Chartrand, T.L., \& Arkin, R.M. (2009). I am too just like you: Nonconscious mimicry as an automatic behavioral response to social exclusion. Psychological Science, 19, 812-822. doi:10.1111/j.1467-9280.2008.02162.x

Masten C.L., Eisenberger N.I., Pfeifer J. H., Dapretto M. (2013). Neural responses to witnessing peer rejection after being socially excluded: fMRI as a window into adolescents' emotional processing. Developmental Science, 16, 743-759. doi:10.1111/desc.12056

Masten C.L., Eisenberger N.I., Pfeifer J.H., Dapretto M. (2010). Witnessing peer rejection during early adolescence: Neural correlates of empathy for experiences of social exclusion. Social Neuroscience, 5, 496-507. doi:10.1080/17470919.2010.490673

Matto, H.C. (2007). Drawings in clinical assessment of children and adolescents. In S.R. Smith \& L. Handler (Eds.), The clinical assessment of children and adolescents: $A$ practitioner's handbook (pp. 207-222). New York, NY: Lawrence Erlbaum. 
Milbrath, C., \& Trautner, H.M. (Eds.). (2007). Children's understanding and production of pictures, drawings and art: Theoretical and empirical approaches. Cambridge, MA: Hogrefe \& Huber.

Neal, J., Neal, Z., \& Cappella, E. (2013). I know who my friends are, but do you? Predictors of self-reported and peer-inferred relationships. Child Development, 85, 1366-1372. doi:10.1111/cdev.12194

Nesdale, D., \& Lambert, A. (2007). Effects of experimentally manipulated peer rejection on children's negative affect, self-esteem, and maladaptive social behavior. International Journal of Behavioral Development, 31, 115-122. doi:10.1177/0165025407073579

Olson, K.R., Newheiser, A., Eason, A.E., \& Hailey, S.E. (April, 2013). Exposure to images of cross-race interaction promotes positive intergroup behavior among children. Talk presented at the Society of Research in Child Development. Seattle, WA.

Novelli, D., Drury, J., \& Reicher, R. (2010). Come together: Two studies concerning the impact of group relations on personal space. British Journal of Social Psychology, 49, 223-236. doi:10.1348/014466609x449377

Over, H., \& Carpenter, M. (2009). Priming third-party ostracism increases affiliative imitation in children. Developmental Science, 12, F1-F8. doi:10.1111/j.14677687.2008.00820.x

R Core Team. (2013). R: A Language and Environment for Statistical Computing. $R$ Foundation for Statistical Computing. Vienna, Austria.

Spoor, J.R., \& Williams, K.D. (2007). The evolution of an ostracism detection system. In J.P. Forgas, M. Haselton, \& W. von Hippel (Eds.), The evolution of the social mind: Evolutionary psychology and social cognition (pp. 279-292). New York: Psychology Press. 
Thomas, G.V., \& Gray, R. (1992). Children's drawings of topics differing in emotional significance - effects on placement relative to a self-drawing: a research note. Journal of Child Psychology, 33, 1097-1104. doi:10.1111/j.1469-7610.1992.tb00928.x

Twenge, J.M., Baumeister, R.F., Tice, D.M., \& Stucke, T.S. (2001). If you can't join them, beat them: Effects of social exclusion on aggressive behavior. Journal of Personality and Social Psychology, 81, 1058-1069. doi:10.1037//0022-3514.81.6.1058

Warburton, W.A., Williams, K.D., \& Cairns, D.R. (2006). When ostracism leads to aggression: The moderating effects of control deprivation. Journal of Experimental Social Psychology, 42, 213-220. doi:10.1016/j.jesp.2005.03.005

Watson-Jones, R.E., Legare, C.H., Whitehouse, H., \& Clegg, J.M. (2014). Task-specific effects of ostracism on imitation in early childhood. Evolution and Human Behavior, 35, 204-210. doi:10.1016/j.evolhumbehav.2014.01.004

Wesselmann, E.D., Bagg, D., \& Williams, K.D. (2009). “I feel your pain”: The effects of observing ostracism on the ostracism detection system. Journal of Experimental Social Psychology, 45, 1308-1311. doi:10.1016/j.jesp.2009.08.003

Will G.-J., Crone, E.A., Van den Box, W., \& Güroğlu, B. (2013). Acting on observed social exclusion: Developmental perspectives on punishment of excluders and compensation of victims. Developmental Psychology, 49, 2236-2244. doi:10.1037/a0032299

Williams, K.D. (2007). Ostracism. Annual Review of Psychology, 58, 425-452. doi:10.1146/annurev.psych.58.110405.085641

Williams, K.D., Cheung, C.K.T., \& Choi, W. (2000). Cyberostracism: Effects of being ignored over the internet. Journal of Personality and Social Psychology, 79, 748-762. doi:10.1037/0022-3514.79.5.748

Zeileis, A., Kleiber, C., Jackman, S. (2008). Regression models for count data in R. Journal of Statistical Software, 27, 1-25. epub.wu.ac.at/1168/ 
Table 1

Summary of Multiple Regression Analyses

\begin{tabular}{|c|c|c|c|c|c|c|}
\hline Variable & $B$ & {$[95 \% \mathrm{CI}]$} & $S E_{B}$ & $\beta$ & $t$ & Adj. $R^{2}$ \\
\hline \multicolumn{7}{|c|}{ Comprehension questions } \\
\hline Step 1 & & & & & & \\
\hline (Constant) & 0.10 & {$[-0.13,0.32]$} & .11 & & & .27 \\
\hline Gender & 0.06 & {$[-0.20,0.31]$} & .13 & .04 & 0.88 & \\
\hline $\begin{array}{l}\text { Age } \\
\text { Condition }\end{array}$ & $\begin{array}{l}0.03 \\
0.55\end{array}$ & $\begin{array}{l}{[0.01,0.05]} \\
{[0.29,0.80]}\end{array}$ & $\begin{array}{r}.01 \\
13\end{array}$ & $\begin{array}{l}.32 * * \\
44 * * *\end{array}$ & $\begin{array}{l}0.43 \\
3.17 \\
4.34\end{array}$ & \\
\hline Step 2 & & {$[0.29,0.00]$} & & .44 & & \\
\hline (Constant) & 0.09 & {$[-0.12,0.31]$} & .11 & & & .32 \\
\hline Gender & 0.06 & {$[-0.19,0.30]$} & .12 & .05 & 0.86 & \\
\hline Age & 0.01 & {$[-0.02,0.03]$} & .01 & .09 & $\begin{array}{l}0.46 \\
0.69\end{array}$ & \\
\hline $\begin{array}{l}\text { Condition } \\
\text { Age } \mathrm{x} \\
\text { Condition }\end{array}$ & $\begin{array}{l}0.55 \\
0.04\end{array}$ & $\begin{array}{l}{[0.30,0.79]} \\
{[0.01,0.08]}\end{array}$ & $\begin{array}{l}.12 \\
.02\end{array}$ & $\begin{array}{l}.44 * * * \\
.33^{*}\end{array}$ & $\begin{array}{l}4.49 \\
2.48\end{array}$ & \\
\hline
\end{tabular}

Protagonist's mood

Step 1

(Constant)

$$
1.61 \quad[1.15,2.07]
$$

$0.34[-0.19,0.87]$

.23

6.96

.16

Gender

$0.02[-0.02,0.06]$

.26

1.29

Age

$-0.96[-1.48,-0.44]$

.02

.14

1.15

Condition

.26

.13

$-3.69$

Step 2

(Constant)

$1.62[1.16,2.08]$

.23

$-.41 *$

6.99

.16

Gender

$0.34 \quad[-0.19,0.87]$

.26

1.29

Age

$0.04 \quad[-0.01,0.09]$

.03

Condition

$-0.97 \quad[-1.49,-0.45]$

.26

.14

1.55

Age $x$

$-0.04 \quad[-0.12,0.04]$

.04

.24

$\begin{array}{ll}. .41 * * * & -3.72\end{array}$

Condition

\section{Children's own mood}

Step 1

$\begin{array}{lrlllrl}\text { (Constant) } & 3.11 & {[2.67,3.54]} & .22 & & 14.26 & -.04 \\ \text { Gender } & 0.01 & {[-0.49,0.50]} & .25 & .003 & 0.02 & \\ \text { Age } & 0.01 & {[-0.03,0.04]} & .02 & .04 & 0.33 & \\ \text { Condition } & -0.14 & {[-0.63,0.35]} & .25 & -.07 & -.57 & \\ \text { Step 2 } & & & & & & \\ \quad \text { Constant) } & 3.10 & {[2.67,3.54]} & .22 & & 14.21 & -.04 \\ \text { Gender } & 0.01 & {[-0.49,0.50]} & .25 & .003 & 0.03 & \\ \text { Age } & -0.01 & {[-0.06,0.04]} & .03 & -.05 & -.30 & \\ \text { Condition } & -0.14 & {[-0.63,0.35]} & .25 & -.07 & -.57 & \end{array}$



Age $\mathrm{x}$
$0.03 \quad[-0.04,0.10]$
.04
.13
0.78

Condition

Adults' rating of affiliation in the drawings

Step 1

$\begin{array}{lrlllr}\text { (Constant) } & 4.50 & {[4.07,4.93]} & .22 & & 20.90 \\ \text { Gender } & -1.19 & {[-1.68,-0.69]} & .25 & -.45^{* * *} & -4.77 \\ \text { Age } & 0.09 & {[0.05,0.13]} & .02 & .44^{* * *} & 4.62 \\ \text { Condition } & 0.51 & {[0.01,1.00]} & .25 & .19^{*} & 2.05\end{array}$

Step 2

(Constant)

$4.51 \quad[4.08,4.95]$

.22

20.95

Gender

$-1.19 \quad[-1.69,-.69]$

.25

$-.45 * * * \quad-4.80$
$.32 *$

Age

0.06

$[0.01,0.12]$

.03

$.32 *$

2.27

Condition

$0.48 \quad[-0.02,0.98]$

.25

.18

1.94

Age $\mathrm{x}$

$0.04 \quad[-0.04,0.12]$

$.04 \quad .15$

1.09

Condition

Time spent on the drawing

Step 1

$\begin{array}{lrlllr}\text { (Constant) } & 2.08 & {[1.98,2.19]} & .05 & & 39.77 \\ \text { Gender } & -0.17 & {[-0.29,-0.05]} & .06 & -.33 * * & -2.81 \\ \text { Age } & 0.002 & {[-0.01,0.01]} & .01 & .06 & 0.49 \\ \text { Condition } & 0.16 & {[0.04,0.28]} & .06 & .31 * * & 2.68\end{array}$

Step 2

$\begin{array}{lrlllrl}\text { (Constant) } & 2.09 & {[1.99,2.19]} & .05 & & 40.52 & .20 \\ \text { Gender } & -0.17 & {[-0.29,-0.05]} & .06 & -.33^{* *} & -2.89 & \\ \text { Age } & -0.01 & {[-0.02,0.01]} & .01 & -.17 & -1.00 & \\ \text { Condition } & 0.15 & {[0.03,0.27]} & .06 & .29 * & 2.56 & \\ \text { Age x } & 0.02 & {[-0.002,0.03]} & .01 & .31 & 1.78 \\ \text { Condition } & & & & & \end{array}$

Number of social elements drawn

Step 1

$\begin{array}{lrlllrl}\quad \text { Constant) } & 11.51 & {[10.48,12.53]} & .51 & & 22.40 & .34 \\ \text { Gender } & -2.57 & {[-3.75,-1.38]} & .59 & -.45^{* * *} & -4.33 & \\ \text { Age } & 0.14 & {[0.05,0.23]} & .05 & .31^{* *} & 3.03 & \\ \quad \text { Condition } & 1.18 & {[0.001,2.36]} & .59 & .21^{+} & 2.00 & \\ \text { Step 2 } & & & & & & \\ \quad(\text { Constant) } & 11.54 & {[10.51,12.57]} & .52 & & 22.41 & .34 \\ \text { Gender } & -2.58 & {[-3.76,-1.39]} & .60 & -.45^{* * *} & -4.35 & \\ \text { Age } & 0.09 & {[-0.05,0.22]} & .07 & .20 & 1.28 & \\ \text { Condition } & 1.12 & {[-0.06,2.31]} & .59 & .20 & 1.90 & \\ \text { Age x } & 0.09 & {[-0.09,0.27]} & .09 & .15 & 1.00 & \\ \text { Condition } & & & & & & \end{array}$

Note. For the categorical variables, $0=$ control condition and $1=$ ostracism condition, and 0

$=$ females and $1=$ males. ${ }^{*} p<.05 . * * p<.01 . * * * p<.001{ }^{*} \mathrm{p}=.050$. 
Ostracism and affiliation 30

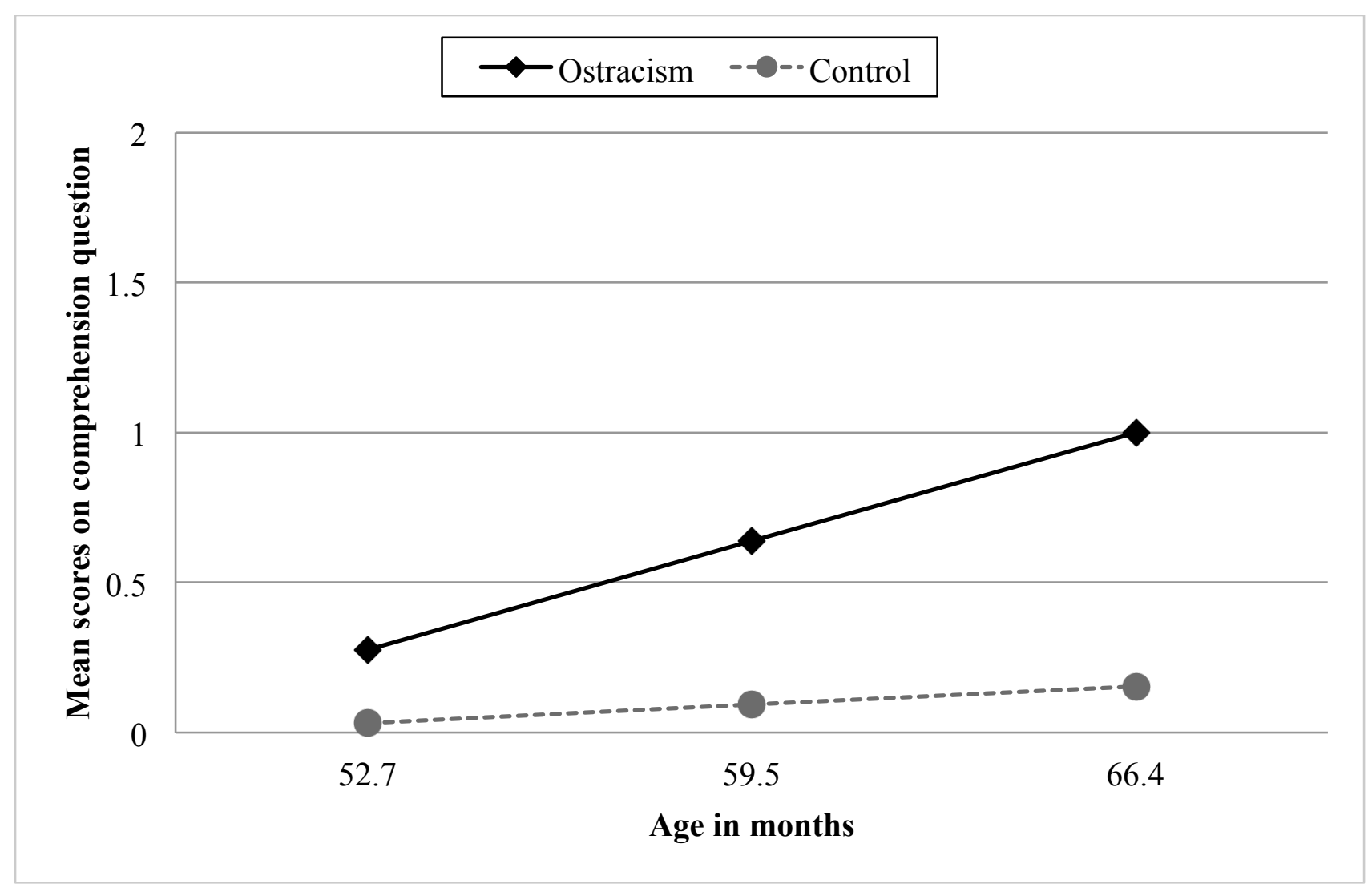

Figure 1. Moderation effect of condition on the relation between age and scores on the comprehension questions. The high (66.4) and low (52.7) values for Age in months are 1 standard deviation above and below the mean age of 59.5 months, respectively. 
a)
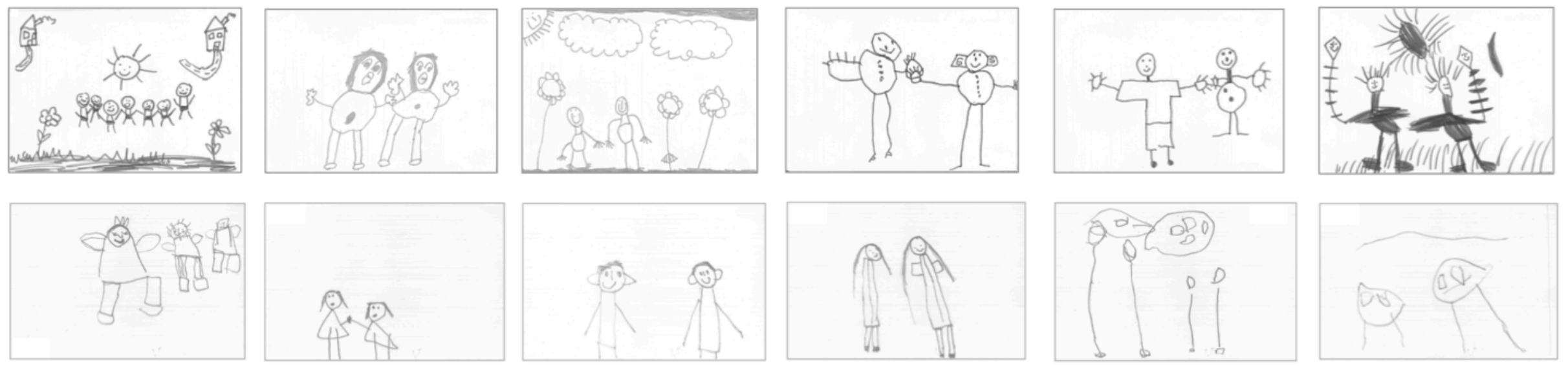

b)
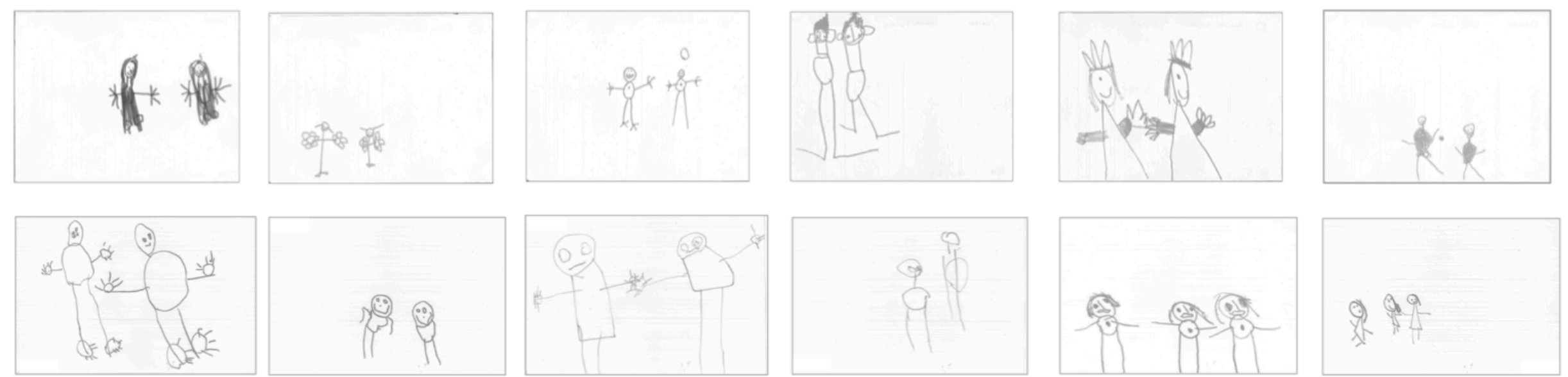

Figure 2. Representative drawings, ordered by age from oldest to youngest, from the a) ostracism condition and b) control condition. 
Figure S1. Individual children's mean scores across the two comprehension questions.

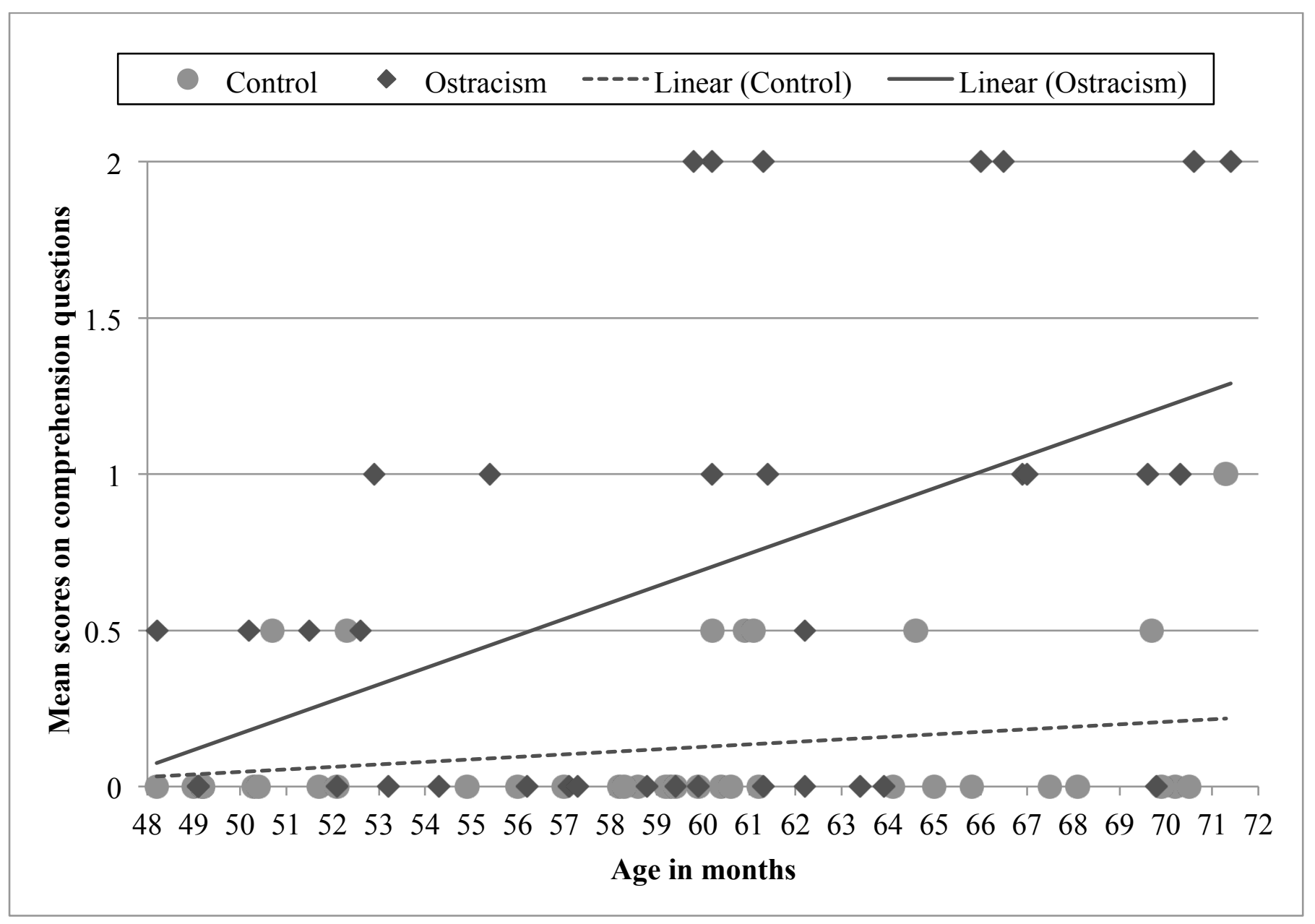


Figure S2. Individual children's mean scores on the two questions referring to the protagonists' mood.

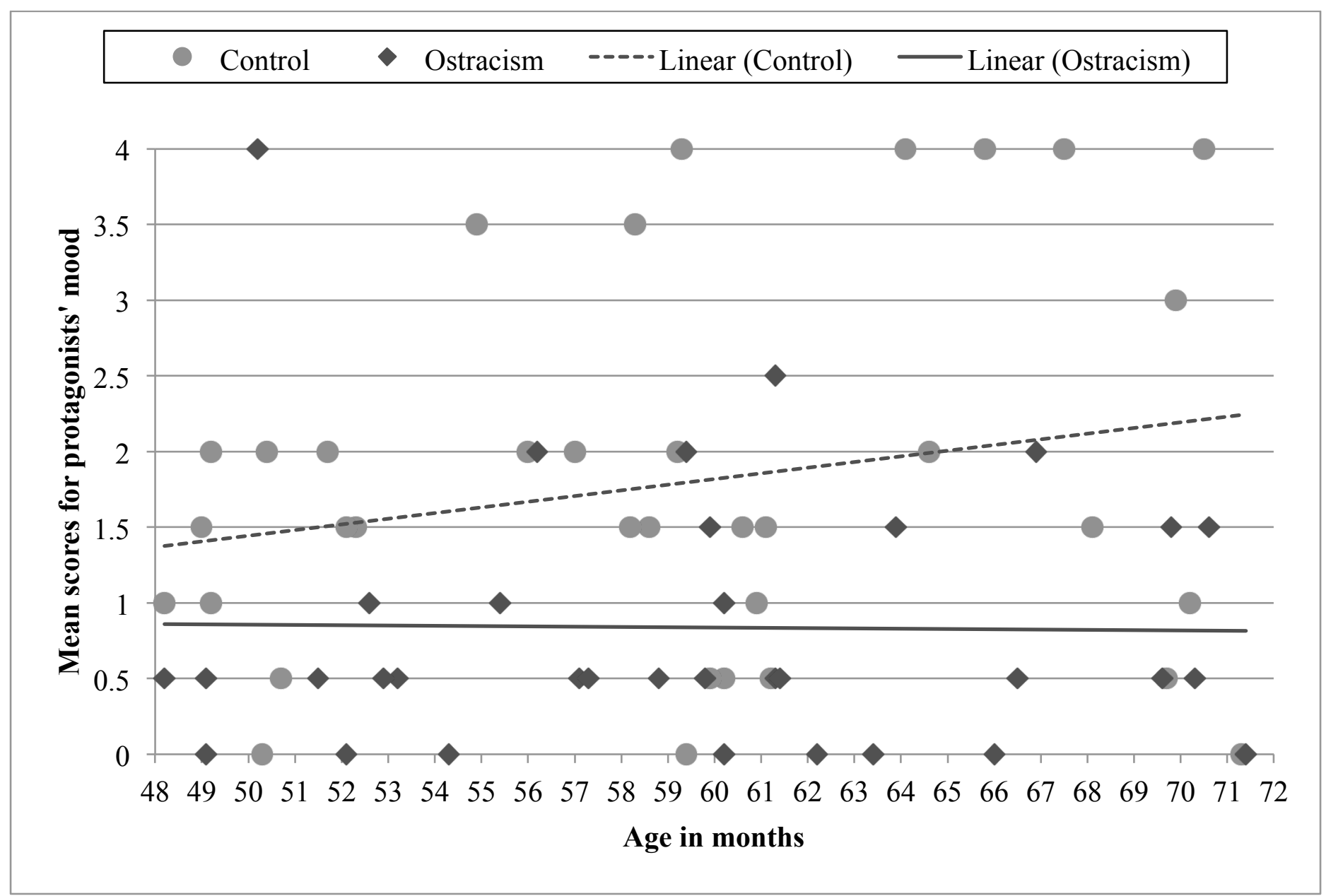


Figure S3. Individual children's mean scores on the two questions referring to children's own reported mood.

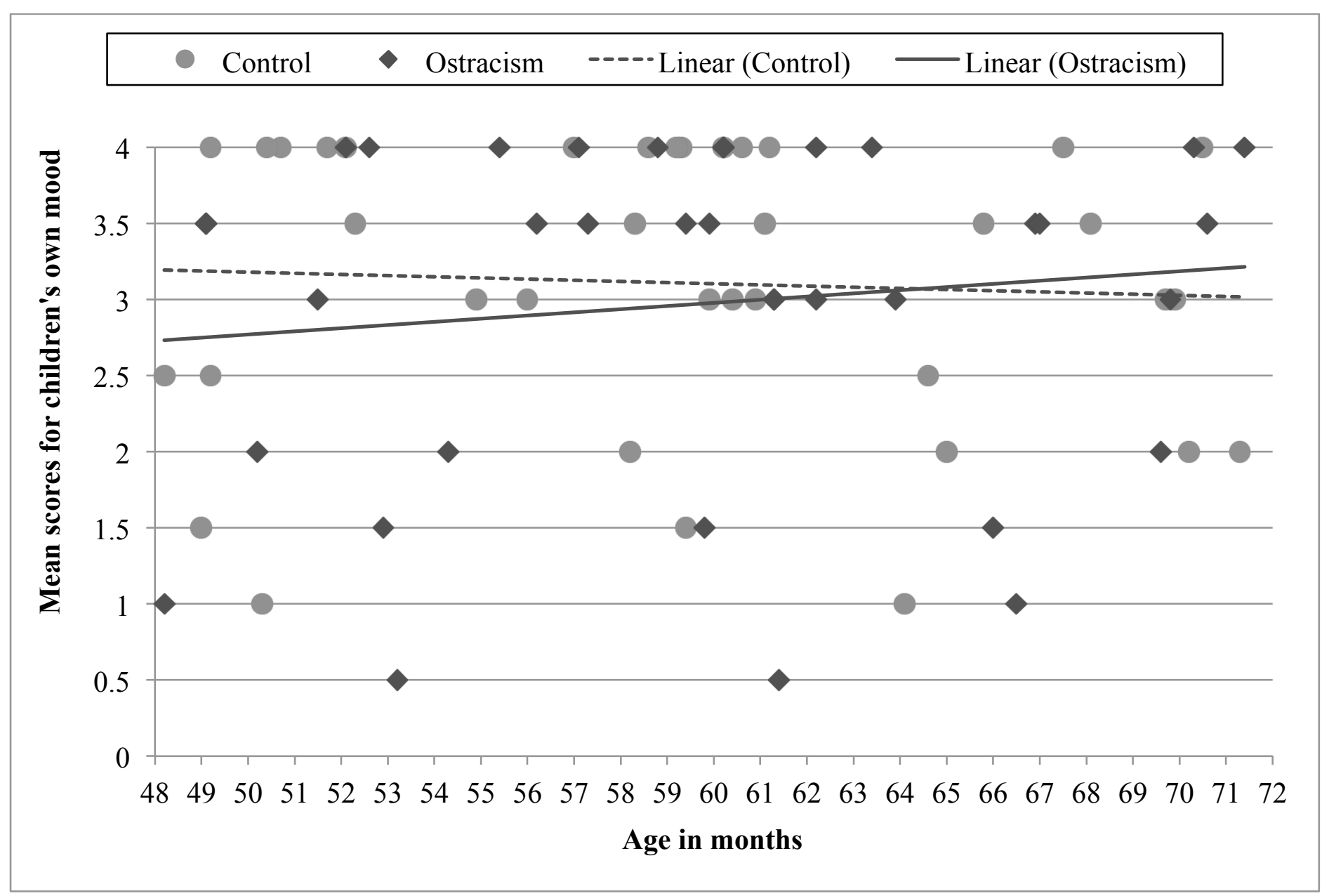


Figure S4. Individual children's results for whether the drawn figures touch or not.

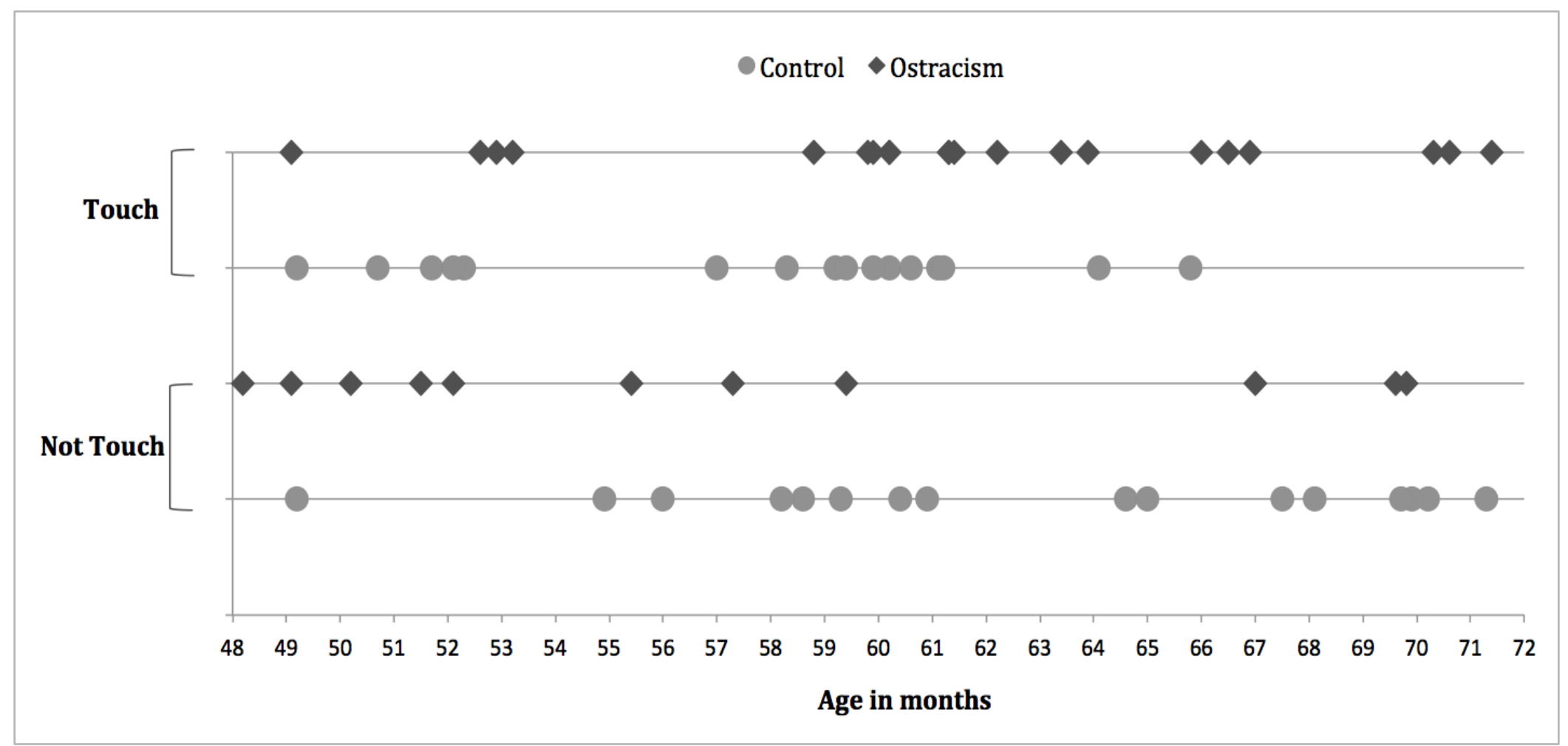


Figure S5. Individual children's results for the distance between the drawn figures (in millimeters)

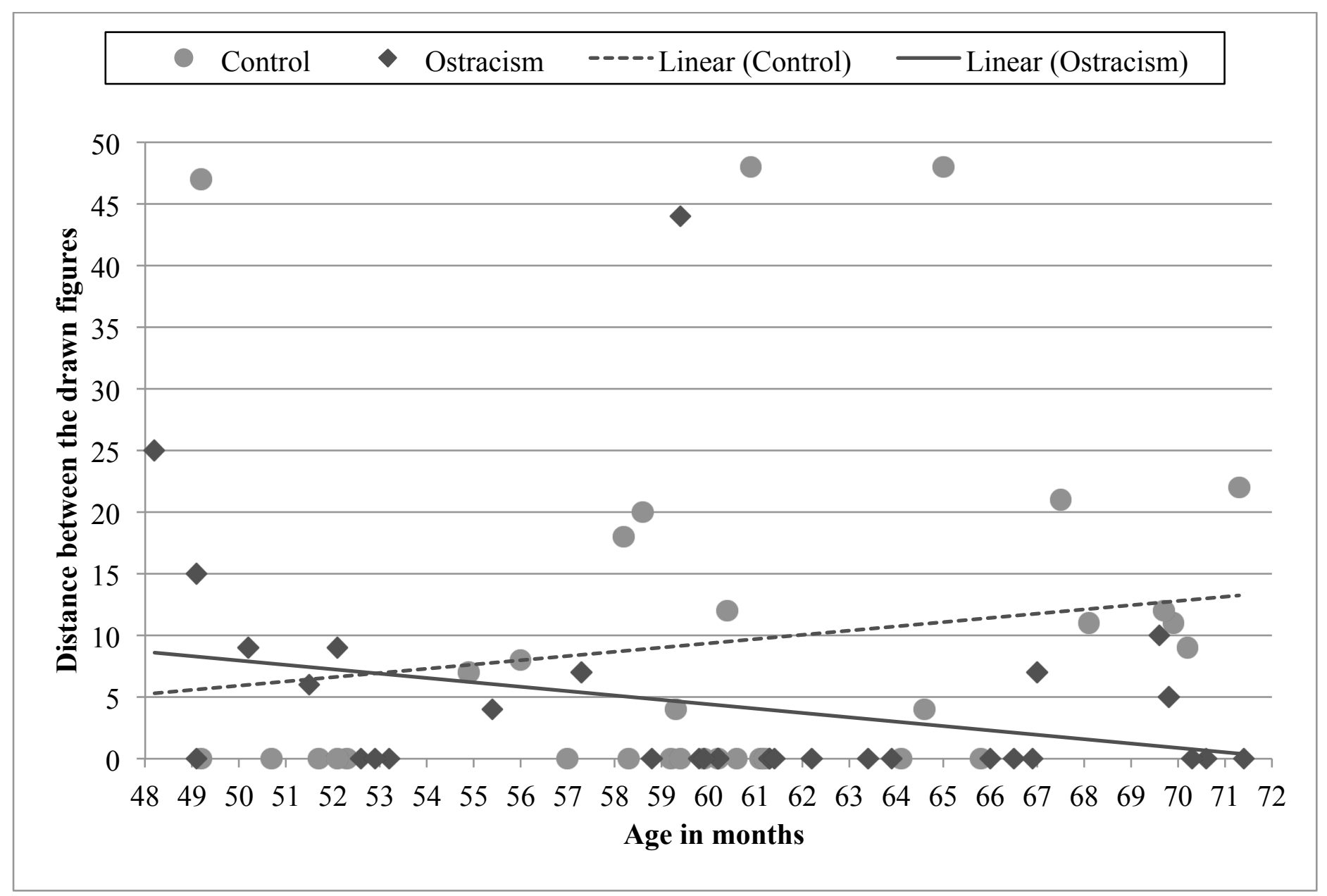


Figure S6. Mean scores from adults' rating of affiliation for each child's drawing.

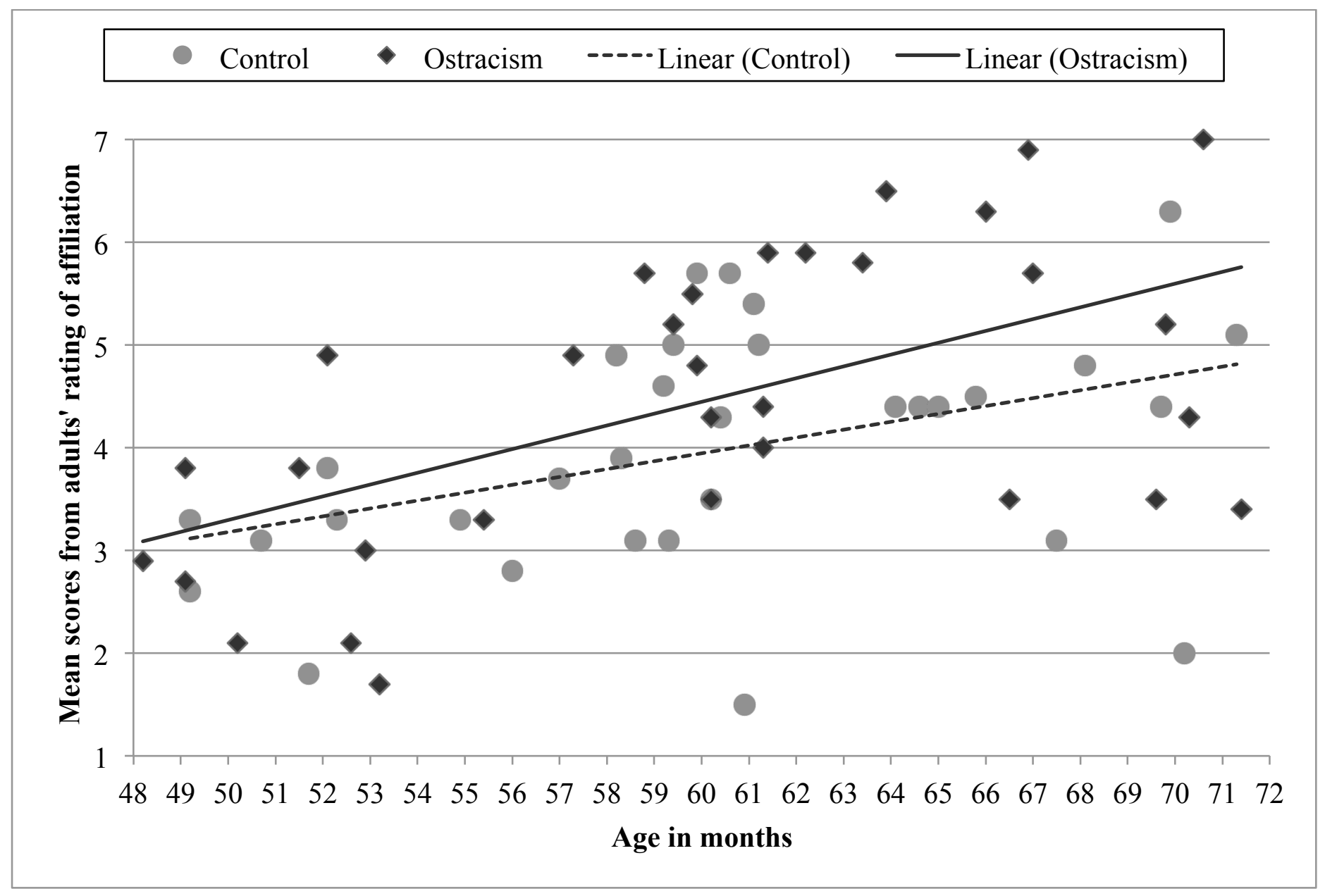


Figure S7. Individual children's time spent on the drawing task (in seconds).

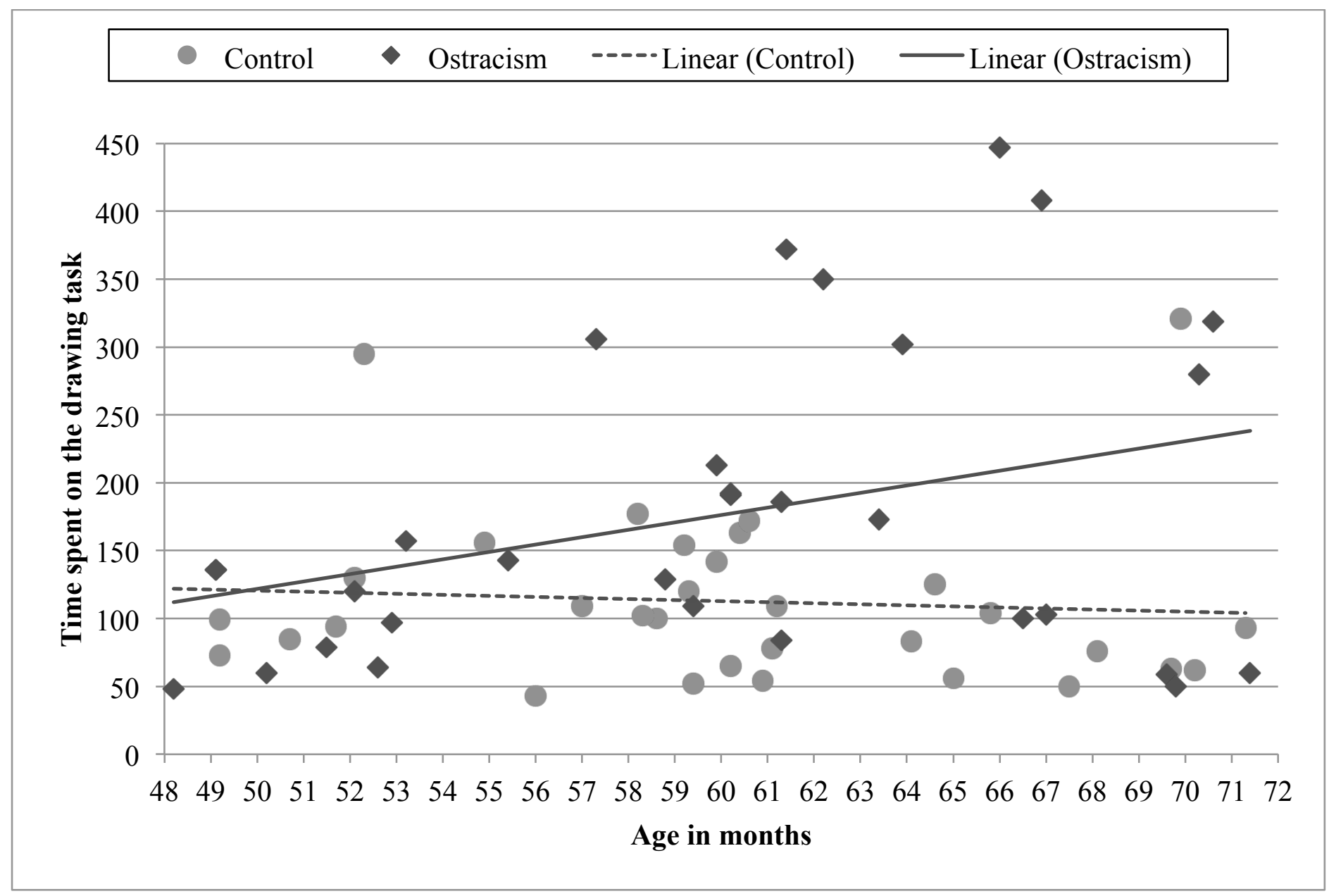


Figure S8. Individual children's results for the number of social elements in the drawing.

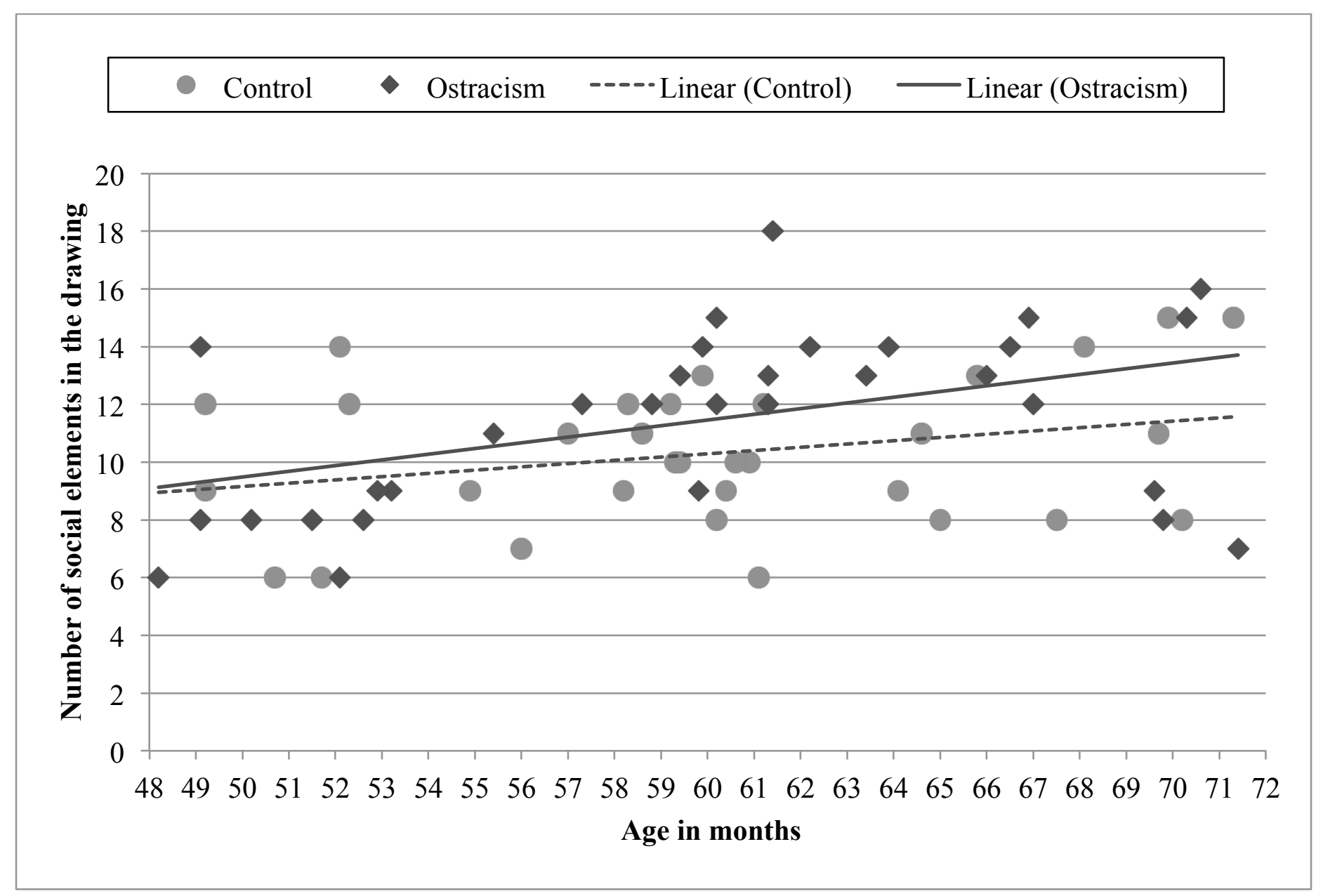

